\title{
Increase in fall-related hospitalizations in the United States, 2001-2008
}

Running title: Increase in fall-related hospitalizations

$\begin{array}{ll}\text { Klaas A. Hartholt } \mathrm{MD}^{1,2} & \text { k.hartholt@erasmusmc.nl } \\ \text { Judy A. Stevens, } \mathrm{PhD}^{3} & \text { jas2@cdc.gov } \\ \text { Suzanne Polinder, } \mathrm{PhD}^{4} & \text { s.polinder@erasmusmc.nl } \\ \text { Tischa J.M. van der Cammen, MD, } \mathrm{PhD}^{2} & \text { t.vandercammen@erasmusmc.nl } \\ \text { Peter Patka, MD, } \mathrm{PhD}^{1} & \text { p.patka@erasmusmc.nl }\end{array}$

${ }^{1}$ Department of Surgery-Traumatology

Erasmus MC, University Medical Center Rotterdam, Rotterdam, The Netherlands

${ }^{2}$ Section of Geriatric Medicine, Department of Internal Medicine

Erasmus MC, University Medical Center Rotterdam, Rotterdam, The Netherlands

${ }^{3}$ National Center for Injury Prevention \& Control,

Centers for Disease Control \& Prevention, Atlanta, Georgia, United States

${ }^{4}$ Department of Public Health, Erasmus MC, University Medical Center Rotterdam, Rotterdam, The Netherlands

\section{Corresponding author}

K.A. Hartholt, MD

Erasmus MC, University Medical Center

Section of Geriatric Medicine, Department of Internal Medicine

PO Box 2040, 3000 CA Rotterdam, The Netherlands

E-mail: k.hartholt@erasmusmc.nl, Tel: +31 1070 35979, Fax: +31 107034768 


\section{Abstract}

Background: The objective was to determine secular trends in unintentional fall-related hospitalizations in people aged 65 and older in the United States.

Materials and Methods: Data were obtained from a nationally representative sample of emergency department visits from January 1, 2001 to December 31, 2008, available through the National Electronic Injury Surveillance System-All Injury Program (NEISS-AIP). These data were weighted to estimate the number, incidence rates and the annual percent change of fallrelated hospitalizations.

Results: From 2001 to 2008, the estimated number of fall-related hospitalizations in older adults increased $50 \%$, from 373,128 to 559,355 cases. During the same time period, the age-adjusted incidence rate, expressed per 100,000 population, increased from 1,046 to 1,368. Rates were higher in women compared to men throughout the study period. The age-adjusted incidence rate showed an average annual increase of 3.3\% (95\% CI: 1.66-4.95).

Discussion: Both the number and rate of fall-related hospitalizations in the United States increased significantly over the 8-year study period. Unless preventive action is taken, rising hospitalization rates in combination with the aging US population over the next decades will exacerbate the already stressed healthcare system, and may result in poorer health outcomes for older adults in the future. Further research is needed to determine the underlying causes for this rising trend. 


\section{Introduction}

Older adults experience falls frequently; approximately one-third of people aged 65 years and older fall at least once a year. ${ }^{1,2}$ Falls are the leading cause of injuries in older adults in the United States and worldwide. Approximately $30 \%$ of falls require medical treatment, ${ }^{3}$ often resulting in emergency department (ED) visits and subsequent hospitalizations, increasing the demand for healthcare services and raising associated healthcare costs. ${ }^{4-6}$ Because the risk of falling increases with age ${ }^{2}$, fall injuries would be expected to increase in the coming decades as the population ages. ${ }^{7}$ We have investigated the impact of an aging society on the demand for fallrelated healthcare in the United States by quantifying hospitalizations following ED visits for fall-related injuries in older adults from 2001 to 2008.

\section{Materials and Methods}

This study analyzed ED data from January 1, 2001 to December 31, 2008 that was obtained from the National Electronic Injury Surveillance System-All Injury Program (NEISS-AIP). NEISSAIP is a collaborative effort by the National Center for Injury Prevention and Control and the Consumer Product Safety Commission and is an expansion of the NEISS. NEISS collects data from 100 hospitals that are a stratified probability sample of all US hospitals (including US territories) that have at least six beds and provide 24-hour emergency services.(8) NEISS-AIP data are collected from about 60 of the 100 NEISS hospitals (the number varies from 60 to 66 , depending on year). The program collects data on initial visits for all types of injuries treated in EDs. From this sample, the total number of injuries treated in hospital emergency rooms 
nationwide can be estimated. Information is abstracted from the medical record and includes data on gender, age, intent of injury (i.e., unintentional, intentional, assault, self harm, and legal intervention), injury mechanism (in general the one most severe injury) and primary diagnosis. Mechanisms of injury were classified by trained coders into major external cause-of-injury groupings using definitions consistent with International Classification of Diseases of the World Health Organization, $9^{\text {th }}$ Revision, Clinical Modifications (ICD-9-CM) external cause coding guidelines.

This study analyzed a sample of 53,009 fall-related injury cases among persons aged 65 years and older who were hospitalized after ED attendance. National estimates were obtained using sample weights assigned to NEISS-AIP cases. Each case initially was assigned a sample weight based on the inverse probability of selection into the NEISS-AIP sample. The inverse of the probability of selection was computed within each of five hospital stratum - four based on size (number of annual ED visits) of the NEISS sample hospital (very large, large, medium and small) and one stratum for children's hospitals. Initial sample weights were then adjusted for nonresponse and post-stratified to weight up to the total number of hospitals with EDs in the year of treatment. Sample weights were post stratified to adjust for changes in the number of US hospital EDs across time. These final sample weights were summed to produce national estimates of fallrelated injuries for persons initially treated in a US hospital ED and then hospitalized. A full description of the survey design and weighting methodology has been published by Schroeder and Ault.(8)

Age-specific incidence rates for 5-year age groups $(65-69,70-74, \ldots, \geq 85$ year) were expressed per 100,000 population, for both men and women. An age-adjusted incidence rate for the overall population aged 65 year and older was calculated by direct standardization to the 2000 
US Census Bureau population estimates, to control for changes in the age distribution among the age 65 and older population during the study period. The adjusted incidence rate allowed us to compare the overall incidence rate throughout the study period. The age-adjusted incidence rate was calculated by applying the observed age-class specific incidence rates, for each 5-year subgroup, for both men and women, to the standard population of 2000, and was expressed per 100,000 population. To model the trend in percent annual change (PAC), logarithms of the hospitalization rates were analyzed using a weighted linear regression model with " $1 /$ variance (rate)" as the weight. A $p$-value of $<0.05$ was considered as statistically significant.

\section{Results}

The absolute number of fall-related hospitalizations in older adults increased 50\% during the study period, from 373,128 in 2001 to 559,355 in 2008. The distribution of hospitalizations between the different age groups is shown in Figure 1. The majority of fall-related admissions occurred in females aged 75 years and over throughout the study period. Both age-specific and age-adjusted incidence rates (per 100,000 population) increased rapidly between 2001 and 2008

(Table 1). The incidence rates were age-related, and increased with age (Figure 2). Age-adjusted incidence rates in males increased from 803.7 (95\% CI: 626.1-981.3) to 1,063.5 (95\% CI: 847.11,280.0) and in females from 1,182.5 (95\% CI: 885.3-1,479.8) to 1,558.8 (95\% CI: 1,200.21,917.3). This reflects a PAC of 3.5\% (95\% CI: 2.15-4.89) in males and 3.3\% (95\% CI: $1.57-$ 5.14) in females. For both males and females, the PAC was higher among the younger age groups (65-69 years) compared to the older age groups. The proportion of cases hospitalized after ED treatment increased slightly, from $23 \%$ in 2001 to $26 \%$ in 2008. In 2008, the most frequent 
primary diagnoses among persons hospitalized for fall-related injuries were fractures (63\%) and contusions or abrasions (13\%), followed by lacerations $(5 \%)$, strain or sprain $(2 \%)$, internal injury (12\%) and other injuries $(5 \%)$.

\section{Discussion}

Epidemiologic information about fall-related injuries is essential for allocating healthcare resources, determining healthcare expenses, and planning for future healthcare needs. This study shows a substantial increase of the number of hospitalized fall-related injuries of $50 \%$ over the last eight years. The age-adjusted incidence rates of fall-related hospitalizations in the United States rose $31 \%$. These increases were seen in both men and women and cannot be explained solely by the growing number of older adults. Similar increasing trends for both fall-related injuries and injury rates have been observed in other western countries such as the Netherlands and Finland. 5,8

There are several possible explanations for the observed increase in fall-related hospitalizations.

The life expectancy in the United States is increasing ${ }^{7}$ and older age is an independent risk factor for falls. ${ }^{2}$ Older adults are living longer with multiple health problems. This would result in an increasing number of frail elderly who are at a high risk for falls, and may explain the increase in age-specific hospitalization rates. Furthermore, older adults are maintaining an active life style and experiencing fewer functional limitations than in the past. ${ }^{9}$ By remaining mobile, older adults actually may be increasing their fall risk.

Higher hospital admission rates may reflect changes in hospital policies that encourage admission following ED treatment as well as the utilization of surgical techniques to improve 
survival and optimize older adults' functional outcomes. ${ }^{10}$ For example, head injuries in older adults are frequently caused by a fall. ${ }^{11}$ Since the introduction in 2000 of revised guidelines for the diagnosis and management of head injuries, the number of head injury admissions has increased in the United States. ${ }^{12}$ However, the overall admission rate after ED presentation due to fall-related injuries remained between $24-26 \%$ during the study period.

Higher incidence rates for fall-related hospitalizations were seen for women in all age groups. This finding is not unexpected and could be partially explained by women's higher prevalence of osteoporosis and increased risk of fractures, compared to men. ${ }^{13}$ In addition, women are more likely to live alone because they have a greater life expectancy. We hypothesize that older women who live alone are more likely to be hospitalized. However, this hypothesis would need to be investigated further.

A limitation of this study is that NEISS-AIP includes only injuries treated in the ED, so only the fall-related injuries that were treated in the ED and subsequently hospitalized were included in our analysis. Although injuries treated in the ED represent the majority of serious fall-related injuries, patients who were admitted directly to the hospital, such as those with hip fracture, were not included in this study. Therefore, the true burden fall-related hospitalizations which would include patients who did not survive treatment in the ED or were directly admitted, likely exceeds the numbers presented in this study.

It has been estimated that the number of persons age 65 years and older in the United States will double in next 30 years, eventually exceeding 80 million persons. ${ }^{7}$ An increasing life expectancy has made people more than age 85 years the fastest growing segment of the population. An important, and increasing segment of this population will be hospitalized for a fall. ${ }^{14,15}$ Unless preventive action is taken, increasing hospitalization rates, combined with the aging of the US population over the next decade, will exacerbate the already stressed healthcare 
system and may result in poorer health outcomes for older adults in the future. The oldest old (aged 85 years and older) are at greatest risk and are 10 times more likely to be hospitalized after a fall compared to persons aged 65-69 years. Therefore, falls prevention programs should pay special attention to this population.

Effective falls prevention interventions have been developed. These include clinical assessment and treatment of fall risk factors; exercise programs that focus on balance and strength training; and multifaceted interventions that include exercise, medication management, vision checking and improvement, and home hazard assessment. ${ }^{16,17}$ However, these interventions have not been widely applied. A variety of effective interventions need to be implemented in the coming years to counteract the expected increase in fall-related injuries in older adults and to limit the associated healthcare costs. ${ }^{6}$

\section{Acknowledgements}

Klaas Hartholt is a research fellow at the Erasmus MC, appointed on a research grant from "the Netherlands Organization for Health Research and Development” (ZonMw), project number 170.885.607. We thank Caspar W.N. Looman MSc. of the Department of Public Health, Erasmus University Medical Center, Rotterdam, The Netherlands for his statistical expertise.

\section{References}

1. Hausdorff JM, Rios DA, Edelberg HK. Gait variability and fall risk in community-living older adults: a 1-year prospective study. Arch Phys Med Rehabil. Aug 2001;82(8):1050-1056.

2. Tinetti ME, Williams CS. Falls, injuries due to falls, and the risk of admission to a nursing home. N Engl J Med. Oct 30 1997;337(18):1279-1284.

3. Stevens JA, Mack KA, Paulozzi LJ, Ballesteros MF. Self-reported falls and fall-related injuries among persons aged>or=65 years--United States, 2006. J Safety Res. 2008;39(3):345-349. 
4. Kocher K, Delinger A. Public health and aging: nonfatal injuries among older adults treated in hospital emergency departments--United States, 2001. MMWR Morb Mortal Wkly Rep. Oct 24 2006;52(42):1019-1022.

5. Hartholt KA, van der Velde N, Looman CWN, et al. Trends in fall-related hospital admissions in older persons in the Netherlands. Arch Intern Med. May 24 2010;170(10):905-911.

6. Stevens JA, Corso PS, Finkelstein EA, Miller TR. The costs of fatal and non-fatal falls among older adults. Inj Prev. Oct 2006;12(5):290-295.

7. Vincent GK, Velkoff VA. THE NEXT FOUR DECADES, The Older Population in the United States:2010 to 2050. Washington, DC: U.S. Census Bureau; May 2010.

8. Kannus P, Parkkari J, Koskinen S, et al. Fall-induced injuries and deaths among older adults. Jama. May 26 1999;281(20):1895-1899.

9. Freedman VA, Martin LG, Schoeni RF. Recent trends in disability and functioning among older adults in the United States: a systematic review. Jama. Dec 25 2002;288(24):3137-3146.

10. Boufous S, Finch C, Close J, Day L, Lord S. Hospital admissions following presentations to emergency departments for a fracture in older people. Inj Prev. Jun 2007;13(3):211-214.

11. Thomas KE, Stevens JA, Sarmiento K, Wald MM. Fall-related traumatic brain injury deaths and hospitalizations among older adults--United States, 2005. J Safety Res. 2008;39(3):269-272.

12. Faul M, Xu L, Wald M, Coronado V. Traumatic Brain Injury in the United States: Emergency Department Visits, Hospitalizations and Deaths 2002-2006. Atlanta (GA): Centers for Disease Control and Prevention National Center for Injury Prevention and Control.; March 2010.

13. Pietschmann P, Rauner M, Sipos W, Kerschan-Schindl K. Osteoporosis: an age-related and gender-specific disease--a mini-review. Gerontology. 2009;55(1):3-12.

14. Hartholt KA, van Beeck EF, Polinder S, et al. Societal consequences of falls in the older population: injuries, healthcare costs and long term reduced quality of life. J Trauma. 2010;In Press DOI: 10.1097/TA.0b013e3181f6f5e5.

15. Stevens JA, Sogolow ED. Gender differences for non-fatal unintentional fall related injuries among older adults. Inj Prev. Apr 2005;11(2):115-119.

16. Stevens JA, Sogolow ED. Preventing Falls: What Works, A CDC Compendium of Effective Community-based Interventions from Around the World. National Center for Injury Prevention and Control of the Centers for Disease Control and Prevention. 2008.

17. Gillespie LD, Robertson MC, Gillespie WJ, et al. Interventions for preventing falls in older people living in the community. Cochrane Database Syst Rev. 2009(2):CD007146. 
Table 1. Numbers and Rates ${ }^{\mathrm{a}}$ of Fall-Related Hospitalizations among People Aged 65 and older Treated in Emergency Departments, by Gender and Age-Group, United States, 2001-2008

\begin{tabular}{|c|c|c|c|c|c|c|c|c|c|}
\hline \multicolumn{9}{|c|}{ Year } & \multirow{2}{*}{$\begin{array}{c}\text { Annual } \\
\text { percentage } \\
\text { changec }^{c}\end{array}$} \\
\hline & 2001 & 2002 & 2003 & 2004 & 2005 & 2006 & 2007 & 2008 & \\
\hline $\begin{array}{l}\text { Age-adjusted incidence } \\
\text { rate for people } \geq 65\end{array}$ & $\begin{array}{c}1,045.6 \\
(803.3-1,287.9)\end{array}$ & $\begin{array}{c}1,066.9 \\
(863.2-1,270.6)\end{array}$ & $\begin{array}{c}1,243.6 \\
(975.6-1,511.6)\end{array}$ & $\begin{array}{c}1,256.6 \\
(972.9-1,540.2)\end{array}$ & $\begin{array}{c}1,221.8 \\
(944.7-1,498.9)\end{array}$ & $\begin{array}{c}1,223.5 \\
(935.2-1,511.8)\end{array}$ & $\begin{array}{c}1,229.4 \\
(935.8-1,523.0)\end{array}$ & $\begin{array}{c}1,368.1 \\
(1,067.8-1,668.4)\end{array}$ & $\begin{array}{c}3.3 \% \\
(1.66-4.95)\end{array}$ \\
\hline Gender \& age-group & & & & $\begin{array}{c}\text { Rate } \\
(95 \% \mathrm{Cl})^{\mathrm{b}}\end{array}$ & & & & & \\
\hline \multicolumn{10}{|l|}{ Men } \\
\hline $65-69$ & $\begin{array}{c}278.2 \\
(206.6-349.8)\end{array}$ & $\begin{array}{c}261.4 \\
(182.6-340.2)\end{array}$ & $\begin{array}{c}278.4 \\
(213.2-343.7)\end{array}$ & $\begin{array}{c}332.6 \\
(259.1-406.2)\end{array}$ & $\begin{array}{c}348.7 \\
(257.1-440.4)\end{array}$ & $\begin{array}{c}325.2 \\
(247.8-402.6)\end{array}$ & $\begin{array}{c}335.7 \\
(254.4-416.9)\end{array}$ & $\begin{array}{c}408.8 \\
(318.6-499.0)\end{array}$ & $\begin{array}{c}5.3 \% \\
(2.92-7.64)\end{array}$ \\
\hline $70-74$ & $\begin{array}{c}412.4 \\
(311.3-513.5)\end{array}$ & $\begin{array}{c}359.0 \\
(281.1-437.0)\end{array}$ & $\begin{array}{c}493.6 \\
(376.2-611.0)\end{array}$ & $\begin{array}{c}542.9 \\
(423.4-662.3)\end{array}$ & $\begin{array}{c}441.3 \\
(326.7-555.8)\end{array}$ & $\begin{array}{c}561.0 \\
(417.3-704.6)\end{array}$ & $\begin{array}{c}494.7 \\
(367.0-622.3)\end{array}$ & $\begin{array}{c}606.1 \\
(468.4-743.7)\end{array}$ & $\begin{array}{c}6.2 \% \\
(1.97-10.61)\end{array}$ \\
\hline $75-79$ & $\begin{array}{c}720.5 \\
(569.6-871.4)\end{array}$ & $\begin{array}{c}706.5 \\
(514.4-898.7)\end{array}$ & $\begin{array}{c}791.2 \\
(5843-998.1)\end{array}$ & $\begin{array}{c}913.6 \\
(673.6-1,153.6)\end{array}$ & $\begin{array}{c}894.7 \\
(657.0-1,132.4)\end{array}$ & $\begin{array}{c}802.6 \\
(575.2-1,030.0)\end{array}$ & $\begin{array}{c}850.9 \\
(626.9-1,075.0)\end{array}$ & $\begin{array}{c}958.8 \\
(747.7-1,170.0)\end{array}$ & $\begin{array}{c}3.8 \% \\
(1.81-5.74)\end{array}$ \\
\hline$\geq 85$ & $\begin{array}{c}2,446.9 \\
(1,731.0-3,162.8)\end{array}$ & $\begin{array}{c}2,681.9 \\
(1,955.2-3,408.6)\end{array}$ & $\begin{array}{c}2,877.5 \\
(2,170.6-3,584.4)\end{array}$ & $\begin{array}{c}2,824.5 \\
(2,059.3-3,589.7)\end{array}$ & $\begin{array}{c}2,710.3 \\
(2,010.4-3,410.1)\end{array}$ & $\begin{array}{c}2,735.0 \\
(1,948.3-3,521.8)\end{array}$ & $\begin{array}{c}2,836.2 \\
(1,983.2-3,689.1)\end{array}$ & $\begin{array}{c}3,063.2 \\
(2,308.0-3,818.3)\end{array}$ & $\begin{array}{c}2.0 \% \\
(0.57-3.54)\end{array}$ \\
\hline \multicolumn{10}{|l|}{ Women } \\
\hline $65-69$ & $\begin{array}{c}323.2 \\
(220.1-426.3)\end{array}$ & $\begin{array}{c}345.4 \\
(270.4-420.4)\end{array}$ & $\begin{array}{c}452.9 \\
(335.5-570.3)\end{array}$ & $\begin{array}{c}467.4 \\
(365.2-570.3)\end{array}$ & $\begin{array}{c}473.6 \\
(327.7-619.6)\end{array}$ & $\begin{array}{c}428.9 \\
(333.6-524.2)\end{array}$ & $\begin{array}{c}425.8 \\
(304.7-546.8)\end{array}$ & $\begin{array}{c}501.3 \\
(358.5-644.2)\end{array}$ & $\begin{array}{c}5.4 \% \\
(1.83-9.04)\end{array}$ \\
\hline $70-74$ & $\begin{array}{c}640.7 \\
(474.7-806.8)\end{array}$ & $\begin{array}{c}609.6 \\
(493.9-725.3)\end{array}$ & $\begin{array}{c}695.9 \\
(523.2-868.5)\end{array}$ & $\begin{array}{c}696.2 \\
(525.3-867.1)\end{array}$ & $\begin{array}{c}706.2 \\
(559.3-867.1)\end{array}$ & $\begin{array}{c}670.9 \\
(482.3-859.5)\end{array}$ & $\begin{array}{c}831.0 \\
(620.3-1,041.7)\end{array}$ & $\begin{array}{c}838.2 \\
(640.1-1,036.2)\end{array}$ & $\begin{array}{c}4.2 \% \\
(2.23-6.10)\end{array}$ \\
\hline $75-79$ & $\begin{array}{c}1,038.0 \\
(775.4-1,300.5)\end{array}$ & $\begin{array}{c}1,116.4 \\
(892.2-1,340.5)\end{array}$ & $\begin{array}{c}1,362.0 \\
(1,056 \cdot 3-1,667.7)\end{array}$ & $\begin{array}{c}1,285.5 \\
(992.4-1,578.6)\end{array}$ & $\begin{array}{c}1,264.1 \\
(976.1-1,552.1)\end{array}$ & $\begin{array}{c}1,281.4 \\
(983.1-1,579.6)\end{array}$ & $\begin{array}{c}1,292.5 \\
(953.3-1,631.6)\end{array}$ & $\begin{array}{c}1,480.2 \\
(1,157.6-1,802.8)\end{array}$ & $\begin{array}{c}4.0 \% \\
(1.81-6.16)\end{array}$ \\
\hline $80-84$ & $\begin{array}{c}1,790.8 \\
(1,335.4-2,246.3)\end{array}$ & $\begin{array}{c}2,024.1 \\
(1,629.4-2,418.8)\end{array}$ & $\begin{array}{c}2,345.1 \\
(1,804.5-2,885.7)\end{array}$ & $\begin{array}{c}2,423.3 \\
(1,804.5-2,885.7)\end{array}$ & $\begin{array}{c}2,208.5 \\
(1,612.0-2,804.9)\end{array}$ & $\begin{array}{c}2,357.6 \\
(1,731.7-2,983.5)\end{array}$ & $\begin{array}{c}2,269.6 \\
(1,718.1-2,821.2)\end{array}$ & $\begin{array}{c}2,402.0 \\
(1,838.9-2,965.1)\end{array}$ & $\begin{array}{c}3.4 \% \\
(1.13-5.81)\end{array}$ \\
\hline$\geq 85$ & $\begin{array}{c}3,743.1 \\
(2,771.9-4,714.2)\end{array}$ & $\begin{array}{c}3,635.7 \\
(2,956.6-4,314.7)\end{array}$ & $\begin{array}{c}4,283.0 \\
(3,330.6-5,235.3)\end{array}$ & $\begin{array}{c}4,108.3 \\
(3,119.1-5,097.5)\end{array}$ & $\begin{array}{c}4,056.6 \\
(3,058.1-5,055.1)\end{array}$ & $\begin{array}{c}4,139.0 \\
(3,061.4-5,216.5)\end{array}$ & $\begin{array}{c}3,955.1 \\
(2,992.5-4,917.6)\end{array}$ & $\begin{array}{c}4,538.2 \\
(3,428.7-5,647.7)\end{array}$ & $\begin{array}{c}2.2 \% \\
(0.37-4.01)\end{array}$ \\
\hline
\end{tabular}

aper 100,000 population

b95\% confidence interval

'The average annual rate of change over the 8-year time period. P-value for trend was $<0.001$ for all age groups 
Figure 1. Number of Fall-Related Hospitalizations in the Older US Population ( $\geq 65$ year) for Age Group and Gender, 2001-2008

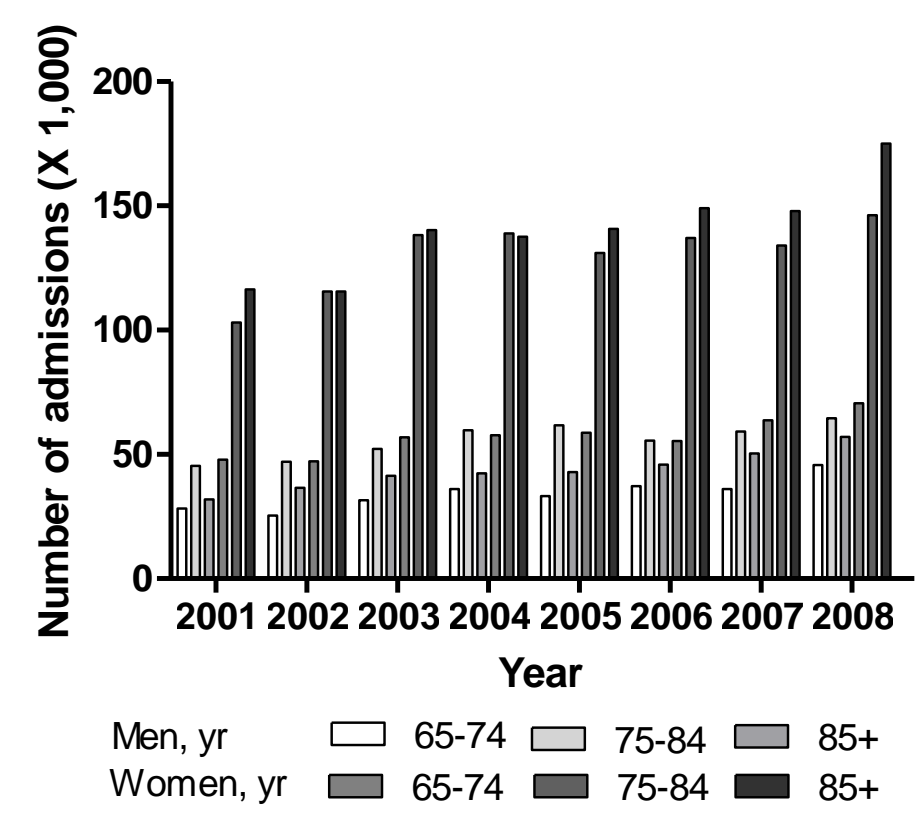


Figure 2. Age-Specific Incidence Rates of Fall-Related Hospitalizations in Persons $\geq 65$ Years, United States, 2001 and 2008

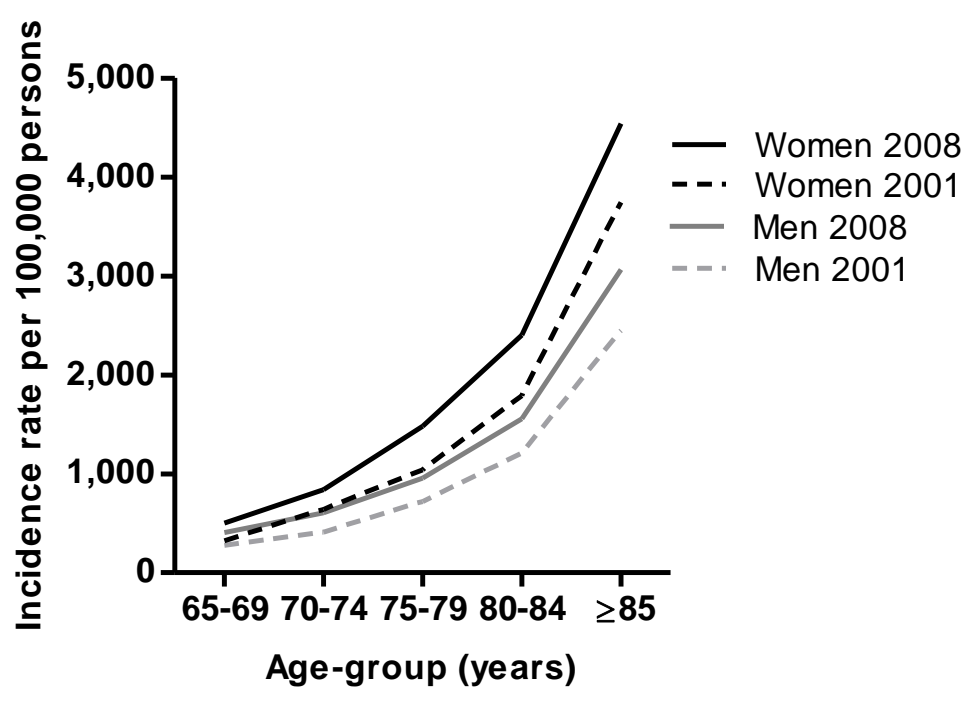

